\title{
A case of episodic congenital complete atrioventricular block
}

\author{
G N Lucas ${ }^{1}$, M A L Faiz ${ }^{2}$ \\ Sri Lanka Journal of Child Health, 2002; 31: 25-6
}

(Key words: congenital complete atriventricular block, CCAVB)

\section{Introduction}

Congenital complete atrioventricular block (CCAVB) occurs in 2 settings characterised by the presence or absence of major congenital anatomic cardiac defects $^{1}$. Certain forms of congenital heart disease have a high association with CCAVB, particularly AV septal defects and those involving abnormalities in the bulboventricular looping such as 1transposition of the great arteries. In this setting, heart block may occur either as the result of fibrous disruption between the atrium and the AV node or due to absence of the penetrating bundles of the AV node $^{2,3}$. CCAVB in the absence of structural heart disease occurs in 1/15,000-1/20,000 live births ${ }^{4}$. An association between maternal connective tissue disease and CCAVB was first demonstrated in $1977^{5}$.

\section{Case report}

A 4 year old boy from Panadura was admitted to the Lady Ridgeway Hospital in September, 2000 with repeated episodes of loss of consciousness from the age of 1 year, each episode lasting a few minutes and being accompanied by pallor and brief tonic-clonic seizure activity. Initially, epilepsy had been diagnosed and the child was treated with carbamazepine with little response. For the last 8 months he was not on anticonvulsant therapy.

On examination, the pulse rate was $72 / \mathrm{min}$, regular and of good volume. The blood pressure was $100 / 60$ $\mathrm{mm} \mathrm{Hg}$. There was a grade 2 ejection systolic murmur best heard in the pulmonary area with fixed splitting of the second heart sound. The chest x-ray showed pulmonary plethora and the ECG showed a partial right bundle branch block. A 2 D echocardiogram confirmed the diagnosis of secundum atrial septal defect.

Although the ECG did not show any evidence of complete heart block, because of the possibility that the seizures were really cardiac syncopal episodes (Stokes Adams attacks) the child was referred to the

${ }^{1}$ Consultant Paediatrician, ${ }^{2}$ Paediatric Registrar, Lady Ridgeway Hospital, Colombo cardiology unit for Holter monitoring. The Holter monitoring showed periods of complete block followed by 2:1 block (Figures $1 \& 2$ ). The child was transferred to the cardiology unit of the National Hospital of Sri Lanka for permanent cardiac pacing.

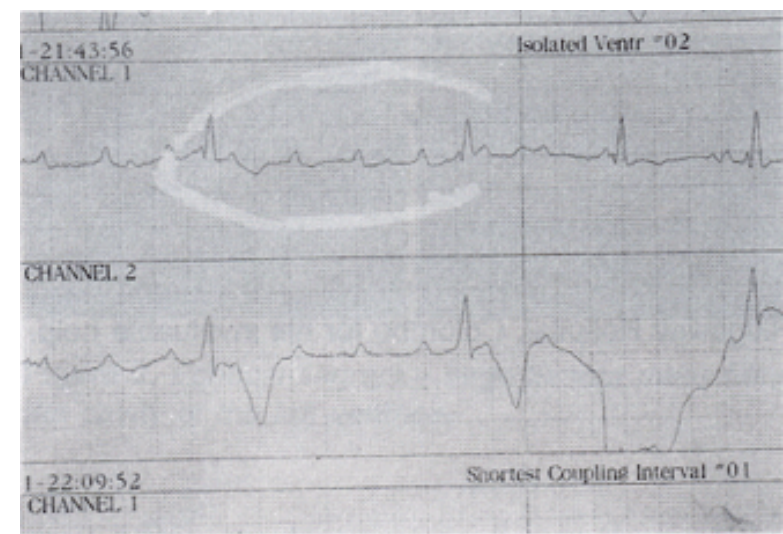

Figure 1 Holter monitoring showing periods of complete heart block

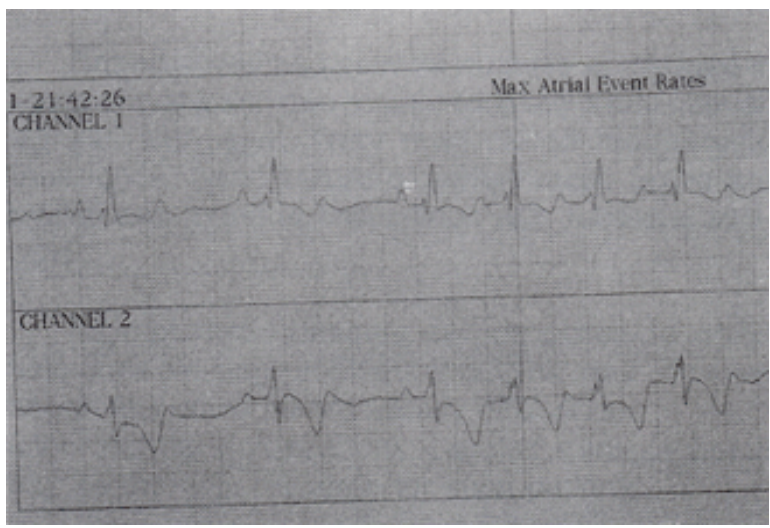

Figure 2 Holter monitoring showing 2:1 heart block

\section{Discussion}

Children with congenital complete atrioventricular block (CCAVB) may present at any age because of symptoms of bradycardia (fatigue or syncope). Many of these children are asymptomatic and are diagnosed because of a low resting heart rate on physical examination ${ }^{6}$. Our case is unusual in that the resting pulse rate was within normal limits. A surface ECG is usually all that is required to make the diagnosis of 
CCAVB. In our patient the routine ECG did not show evidence of CCAVB and a 24-hour rhythm recording (Holter monitor) was necessary to establish the diagnosis. Cardiac syncopal episodes in CCAVB can be accompanied by brief tonic or clonic seizure activity which occur 10-20 seconds after the onset of asystole, is usually of short duration with no subsequent post-ictal phase ${ }^{7}$. It is not surprising that an initial diagnosis of epilepsy was made in our patient. The mainstay of treatment for symptomatic CCAVB is permanent cardiac pacing ${ }^{6}$.

\section{Acknowledgements}

We thank Dr S Narenthiran, cardiologist, Lady Ridgeway Hospital, Colombo for his invaluable help

\section{References}

1. Lev M. Pathogenesis of congenital atrioventricular block. Prog Cardiovasc Dis 1972; 15: $145-57$.

2. Lev M, Silverman J, Fitzmaurice F M, Paul M H, Cassels D E, Miller R A. Lack of connection between the atria and the more peripheral conduction system in congenital atrioventricular block. Am J Cardiolog 1971; 27: 481-8.
3. Lev M, Cuadoros H, Paul M H. Interruption of the atrioventricular bundle with congenital atrioventricular block. Circulation 1971; 43: 70310.

4. Michaels M, Engle M A. Congenital complete heart block: an international study of the natural history. Cardiovasc Clin 1972; 4: 85-101.

5. Chameides L, Trex R C, Vetter V, Rashkind W J, Galioto F M Jr, Noonan J A. Association of maternal systemic lupus erythematosus with congenital complete heart block. $N$ Engl $J$ Med 1977; 297: 1204-7.

6. Case C L. Diagnosis and treatment of pediatric arrhythmias. Pediatr Clin North Am 1999; 46: 347 54.

7. Lewis D A, Dhala A. Syncope in the pediatric patient - the cardiologist's perspective. Pediatr Clin North Am 1999; 46: 205-19. 
